\title{
The availability and limitation of Geophysics at the On-Site Inspection
}

\author{
Xinjun Li, Muen Tang, Qiang Tan, Xue Kong, Zenghu Ma \\ Northwest Institute of Nuclear Technology \\ Xi'an ,China
}

\begin{abstract}
Based on the generic name of Continuation Period Techniques (CPT), various different and effective geophysical techniques are covered. According to the Paragraph 69, Part II of the Protocol to the Comprehensive Nuclear-Test-ban Treaty(CTBT), the techniques allowed once the continuation of the inspection has been approved. Geophysical inspection techniques are employed, especially when results coming from the initial inspection period indicate that further examinations are in need for further examinations. The paper introduces the CTBT which provides geophysical verification technology and states its availability and limitation at the On-site inspection (OSI).
\end{abstract}

Keywords-CTBT; geophysical; OSI; availability and limitation

\section{INTRODUCTION}

One of the significant roles of an On-Site inspection (OSI) is that it must refine the reported location of an ambiguous event or any possible event which would threaten national security to a small enough area in order to allow agreed technologies to resolve the nature of the event (Fig.). Geophysical verification technology is one of the widely used methods for accomplishing the location refine in an inspection.

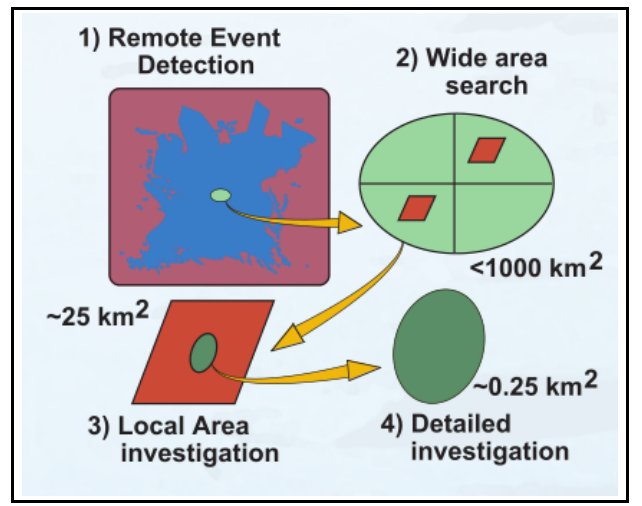

Fig. 1 Process and steps of location event

According to the Treaty ${ }^{[1]}$, \&69: The following inspection activities may be conducted and techniques are used, in accordance with the provisions on managed access, [...]:

(f) Resonance seismometry and active seismic surveys to search for and locate underground anomalies, including cavities and rubble zones; (g) Magnetic and gravitational field mapping, ground penetrating radar and electrical conductivity measurements at the surface and from the air, as appropriate, to detect anomalies or artifacts; ...

Therefore, the techniques allowed once the continuation of the inspection has been approved are resonance and active seismic, magnetic and gravitational field mapping, ground penetrating radar and electrical conductivity measurements, operating at the surface and from the air.

\section{The Precondition of Geophysical Methods at the Osi}

The physical properties of the rock will change, no matter how small it is: for instance, changes in the water table, conduce to cave, Rock Fragmentation, ..., etc after the underground nuclear explosion (Fig. 2). Meanwhile, the characteristics of geophysical field will change, to name a few, electrical resistivity, gravity field, magnetic field, the wave velocity of rock ${ }^{[2,3,4]}$.



Fig. 2 The cave and rock fragmentation field of underground nuclear explosion(Albert Smith,2009)

To date, surface geophysical methods, common in nearsurface mineral prospecting and engineering, and geophysics are to be used in general during the continuation period to identify infrastructure elements of an underground nuclear explosion, such as adits, tunnels, pipes or cables. Others help 
point to changes in the geological structures caused by such an explosion.

OSI-related geophysical operations will have special requirements. Such as:

1) to get practice in speeding up the application of geophysical methods in mapping limited areas which outlined by OSI procedure.

2) to test field data acquisition and interpretation procedure with "quick and dirty", which is on-site and "over-night" computerized processing methods.

3) to get practice in synergic evaluation of survey data provided by different geophysical methods.

\section{The Methods OF GeOPhysicAl AT THE OSI}

To reach the operational level, we need to analyses the methods of the CTBT which provides geophysical verification technology availability and its limitation at the OSI. According to the treaty and Integrated Field Exercise (IFE) of CPT, the methods of geophysical technology at the OSI include: Magnetic, Electrical conductivity measurements, GPR, Gravitational measurement, Aftershock monitoring, Seismic surveys, etc.

\section{A. Magnetic}

Magnetic field mapping measures deviations in the Earth's magnetic fields which may result from different ironcontaining objects in the ground. The presence of such objects can point to infrastructure elements of an underground nuclear explosion, such as pipes and cables. In addition, Magnetic detectors help identifying man-made structures in the ground, such as foundations or shafts.

Aerial magnetic field mapping is valuable to narrow down the area and guide the other OSI activities, which carried out at 20 sites of UNE and magnetic anomalies were detected. Nevertheless, this method maybe affected by flying parameters and the weather easily to some extent, and high intrusion because it probes into some sensitive facilities irrelevant to inspection. Ground magnetic is employed during the continuation period to identify anomalies in the underground geological structures. Figure 3 shows the capability of the technique during IFE $08^{[5]}$.

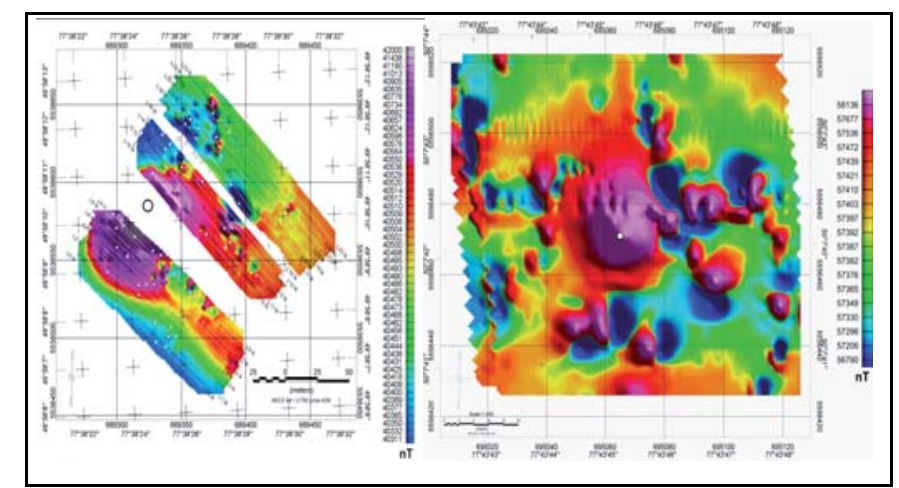

Fig.3 Total magnetic field over reduced to the pole over abandoned Bh129,130

\section{B.GPR}

Ground penetrating radar(GPR) uses electromagnetic waves to locate objects in the ground. The radar emits electromagnetic waves into the ground where they may reflect on certain objects ${ }^{[6]}$. The reflected waves, then, allow for the identification of these objects and their location. Higher frequencies correspond to shorter waves. Additionally, the shorter the wave is , the smaller the buried objects that will be detected. This technology is used to identify parts of an explosions infrastructure in the ground. GPR will detect shallow anomaly, effective depth of detection is not more than $30 \mathrm{~m}$, useless at resistivity less than 50 ohm-meter. Detection depth can be down in which exit high conductivity overlay. Obviously, it clearly depicts that the detected result is excellent.

\section{C.Gravitational Field Mapping}

Gravitational field mapping is used to search for changes in the density of the rock and helpful to locate the cavity created by an underground nuclear explosion. A cavity, or a void, represents a change in the density of the rock compared with surrounding rocks. The size of a cavity depends on various factors, such as the yield of the explosion, the depth and the surrounding geology. On the basis of the rock type, a one kiloton explosion at a depth of 200 meters could cause a cavity of approximately 17 meters in diameter ${ }^{[7]}$. However, gravitational anomaly is so small that it is very difficult to identify from the background, slow and intricate to execute. Topography knowledge with a relative accuracy of $1 \mathrm{~cm}$ in altitude is required at each measurement point.

\section{Electrical Conductivity Measurements}

There are two distinct purposes of electrical conductivity measurements during an on-site inspection. Shallow measurements, up to five meters depth, of underground electrical properties can help identify metallic objects belonging to the infrastructure of a possible nuclear explosion. Deeper measurements will lead the inspectors to identify disturbances in the underground geological structures, such as cavities or changes in the water table, which, in both cases, may result from an underground nuclear explosion.

Transient Electromagnetic method (TEM) can locate the cave of an underground nuclear explosion ${ }^{[8]}$. When the diameter of an underground cavity is approximately one tenth of the buried depth, resistivity image with good resolution will be obtained in the depth between $10 \mathrm{~m}$ to $1000 \mathrm{~m}$. But complicated geology makes interpretation difficult, it is not efficient in location in undulation topography and easily disturbed by man-made electromagnetic.

Vertical electrical resistivity (VES) is a versatile and sample method to detect conductive layers and resistive objects. Highly effective if using multi-electrode systems, it has high resolution power by homographic 3D processing. But this method is can be down in which exit low conductivity overlay $^{[9]}$.

\section{E.Active seismic surveys}

High resolution seismic surveys are conducted to identify changes and disturbances in the underground geological 
structures. Seismic surveys is vital to detect the cave and rock fragmentation, refine the location of the nuclear detonation, though it is not time-saving or efficiency enough ${ }^{[10]}$.

\section{F.Aftershock Monitoring}

Seismic technology is used preferably at the beginning of an on-site inspection as the number of seismic aftershocks after a nuclear explosion decreases rapidly. An underground nuclear explosion would create a cavity and changes in the geological surroundings. Following a nuclear explosion, geological structures at the site of the explosion will settle, causing minute seismic events with distinct seismic signatures that can be detected by what is called passive seismological monitoring.

Aftershocks continue for weeks following an explosion, refining the location of the nuclear detonation, this method can only play a limited role according to present studies ${ }^{[11]}$. But it could not discrimination of nuclear explosions and chemical explosions, and the number of aftershocks greatly depends on local geological conditions.

Additionally, a detailed demonstration of these methods of OSI geophysical technology discussed in this section is listed in Table I below ${ }^{[12]}$.

TABLE I. THE METHODS OF OSI GEOPHYSICAL TECHNOLOGY

\begin{tabular}{|c|c|c|c|}
\hline Methods & Object & $\begin{array}{l}\text { Detection } \\
\text { Depth }\end{array}$ & Limitation \\
\hline $\begin{array}{l}\text { Aerial } \\
\text { Magnetic }\end{array}$ & Boreholes & -- & $\begin{array}{l}\text { Depends on } \\
\text { environment } \\
\text { and the weather }\end{array}$ \\
\hline $\begin{array}{l}\text { Ground } \\
\text { Magnetic }\end{array}$ & $\begin{array}{c}\text { Metallic } \\
\text { structures(Pipes } \\
\text { and cables) }\end{array}$ & $<20 m$ & $\begin{array}{l}\text { Vulnerable to } \\
\text { interference }\end{array}$ \\
\hline VES,TEM & $\begin{array}{c}\text { Resistivity } \\
\text { anomaly } \\
\text { (Infrastructure or } \\
\text { disturbances of } \\
\text { pipe, cave, changes } \\
\text { in the water table) }\end{array}$ & $\begin{array}{c}\mathrm{n} \times 10- \\
\mathrm{n} \times 100 \mathrm{~m}\end{array}$ & $\begin{array}{l}\text { Difficult at high } \\
\text { resistivity/cond } \\
\text { uctivity overlay }\end{array}$ \\
\hline GPR & $\begin{array}{c}\text { Shallow anomaly } \\
\text { (Infrastructure), } \\
\text { Fault }\end{array}$ & $<30 m$ & $\begin{array}{l}\text { The limitation } \\
\text { of depth, } \\
\text { Vulnerable to } \\
\text { interference }\end{array}$ \\
\hline Gravity & $\begin{array}{c}\text { Cave or void(Hard } \\
\text { rock) }\end{array}$ & $10 \mathrm{~m}-1000 \mathrm{~m}$ & $\begin{array}{c}\text { Slow, intricate } \\
\text { and difficult at } \\
\text { mountainous }\end{array}$ \\
\hline $\begin{array}{l}\text { Active } \\
\text { seismic }\end{array}$ & $\begin{array}{l}\text { Increased } \\
\text { fracturing in the } \\
\text { rock and its } \\
\text { changing porosity } \\
\text { (Cave ,Fault) }\end{array}$ & $\begin{array}{c}\mathrm{n} \times 10- \\
\mathrm{n} \times 100 \mathrm{~m}\end{array}$ & $\begin{array}{l}\text { Slow, intricate } \\
\text { of interpret }\end{array}$ \\
\hline Aftershock & $\begin{array}{l}\text { Minute seismic } \\
\text { events }\end{array}$ & -- & $\begin{array}{l}\text { Depends on } \\
\text { geological } \\
\text { conditions }\end{array}$ \\
\hline
\end{tabular}

\section{OBSERVATIONS}

This exercise we discussed in this study demonstrates the geophysical verification technology and its availability and limitation at the OSI. We propose that the key criterion of evaluating the availability of OSI geophysical technology is to confirm and can play effective role. It is not possible to confirm this scope merely by several experiments.

In order to evaluate the availability of OSI geophysical technology, the phenomena and characteristics of nuclear explosions need further exploration. Theoretical research about phenomenology of underground nuclear explosions should be strengthened, which is of great value to confirm the effective scope of OSI.

In addition, the availability of geophysical technologies at OSI should be re-evaluated with the development of equipments and software.

\section{REFERENCES}

[1] Preparatory commission the Comprehensive Nuclear-Test-Ban Treaty Organization(CTBTO), comprehensive nuclear-test-ban treaty (CTBT), 1996.

[2] Howard C. Rodean, Understanding and Constructively Using the Effects of Underground Nuclear Explosions, Reviews of Geophysics, Vol.6(3), 1968.

[3] Knox Joseph,B., Rawson Donald E. and Korner John A., Analysis of groundwater anomaly created by an underground nuclear explosion, Journal Geophysical Research,70(4):823-835, 1965.

[4] S.Derlich, Underground nuclear explosion effects in granite rock fracturing, Proc. Symp. on Eng. with Nuclear Explosives, pp.508-518, January1970.

[5] Luis R.Gaya-Piqué, Rainier Arndt and IFE08 CPT subteam, Geophysical techniques for on-site inspections-experience and overview. CTBT: International scientific studies 2009(ISS09), 2009.

[6] Li Chuanying, Feng Diqing, Studies on the application of GPR in OSI for CTBT, Proceedings of the $9^{\text {th }}$ national conference on nuclear electronics \&nuclear detection technology,411-413, 1998.

[7] CJS Fourie, R. Murdie, L.R.Gaya-pique, The limitations of the gravity technique when investigating a possible ground zero, CTBT: International scientific studies 2009(ISS09), 2009.

[8] Han Jimin, Zhao Guoze, Transient electromagnetic anomalies characteristics of the cave of underground nuclear explosion, The Second Academic Seminar of National Security Geophysics , 2006.

[9] Mattbew B.J. Purss, Rutb Murdie, Ray Tracey, Asbley Grant, etc,Integrated Geophysical investigations under the OSI regime:detection of cavities in a karst area, CTBT: International scientific studies 2009(ISS09), 2009.

[10] A.Belyashow, V.Suvorov, and E.Melnik, Results of seismic study on the upper part of the section at semipalatinsk test site area(for OSI purposes ), CTBT: science and technology 2015 conference, 2015.

[11] Albert Smith, Alexander Spivak, Zhenfu Li, and Svetlana Kishkina, Passive seismic monitoring of aftershocks during an on-site inspection, CTBT: International scientific studies 2009(ISS09), 2009.

[12] Xiaoyuan Han, Mingyan Jia, Bing Gong, Mei Tian, Hui Xu, The availability and limitation of techniques for on-site inspection, CTBT: International scientific studies 2009(ISS09), 2009. 